\title{
Identification of Mycobacteria by Thin Layer Chromatographic Analysis of Mycolic Acids and Conventional Biochemical Method: Four Years of Experience
}

\author{
Clarice Queico Fujimura Leite ${ }^{+}$, Clovis Wesley Oliveira de Souza*, \\ Sergio Roberto de Andrade Leite**
}

\begin{abstract}
Faculdade de Ciências Farmacêuticas, Universidade Estadual Paulista, Caixa Postal 502, 14801-970
Araraquara, SP, Brasil *Departamento de Saúde Pública, Universidade Federal de São Carlos, São Carlos, SP, Brasil **Instituto de Química, Universidade Estadual Paulista, Araraquara, SP, Brasil
\end{abstract}

\begin{abstract}
Mycolic acids analysis by thin-layer chromatography (TLC) has been employed by several laboratories worldwide as a method for fast identification of mycobacteria. This method was introduced in Brazil by our laboratory in 1992 as a routine identification technique. Up to the present, 861 strains isolated were identified by mycolic acids TLC and by standard biochemical tests; $61 \%$ out of these strains came as clinical samples, $4 \%$ isolated from frogs and $35 \%$ as environmental samples. Mycobacterium tuberculosis strains identified by classical methods were confirmed by their mycolic acids contents (I, III and IV). The method allowed earlier differentiation of $\mathrm{M}$. avium complex - MAC (mycolic acids I, IV and VI) from M. simiae (acids I, II and IV), both with similar biochemical properties. The method also permitted to distinguish $\mathrm{M}$. fortuitum (acids I and V) from M. chelonae (acids I and II), and to detect mixed mycobacterial infections cases as $\mathrm{M}$. tuberculosis with MAC and M. fortuitum with MAC. Concluding, four years experience shows that mycolic acids TLC is an easy, reliable, fast and inexpensive method, an important tool to put together conventional mycobacteria identification methods.
\end{abstract}

Key words: mycobacteria identification - mycolic acids - thin layer chromatography

After years of declining case rates, tuberculosis is again a major public health problem in Brazil and in other developing countries (Hijjar 1992). The emergency of AIDS augmented the incidence of infections with other mycobacteria that live in the environment and are resistant to antituberculosis drugs (Kritske et al. 1995). However the identification of Mycobacterium species through morphological, cultural and biochemical tests, requires several weeks or even months of fastidious work (Wayne et al. 1991). DNA probe analysis is a fast and trusty method, but needs a specific probe for each species, resulting expensive. The utilization of different chemical methods has greatly improved the classification and identification of mycobacteria (Luquin et al. 1991, Hines \& Fraziers 1993, Leite et al. 1995). Chemical analysis of cellular fatty acids, especially of those with high molecu-

\footnotetext{
This work was supported by Fapesp (Brazil) grant no. 89/3474-2

${ }^{+}$Corresponding author. Fax: $+55-16-232-1576$ or 222.0073. E-mail: leite@iq.unesp.br

Received 11 March 1998

Accepted 30 July 1998
}

lar-weight a-branched b-hydroxylated chain, the mycolic acids, has been used as a rapid test for mycobacterial systematics (Lévy-Frébault et al. 1986, Butler \& Kilburn 1990).

Mycolic acid methyl ester analysis by thin layer chromatography (TLC) has been employed by several laboratories worldwide as a fast method for identification of clinical (Lévy-Frébault et al. 1987) and environmental (Falcão et al. 1993) isolated mycobacteria. Mycolic acids can be resolved into several classes according to the presence of different functional groups in their molecules. Partial congruence is found between the distribution of mycolic acids types and the finer taxonomic relationships among the mycobacteria as shown in $16 \mathrm{~S}$ rRNA studies (Goodfellow \& Magee 1998). In spite of its advantages, the method was introduced in Brazil as a routine identification technique only in 1992 by our laboratory (Leite et al. 1995). The purpose of this study is to present our four years experience of using TLC associated to conventional biochemical identification methods in a Brazilian mycobacteriology laboratory.

\section{MATERIALS AND METHODS}

Reagents and culture media - Diazomethane was prepared by reaction of nitrosomethylurea 
(synthesized in our laboratory) with potassium hydroxide. All the reagents and solvents utilized were of analytical grade. The silica gel plates for TLC chromatography were from Merck and Sigma. Lowenstein-Jensen culture medium was prepared at our laboratory.

Bacterial strains and growing conditions - A total of 861 strains were tested: 532 human isolates came from Sanatory Hospital, 56 frog isolates (frog raising) and 273 environmental isolates (swimming pools, rivers, aquarium and drinking waters). The type strains M. avium CIPT 14031001, M. chelonae CIPT 14042003, M. fortuitum CIPT 14041001 and M. tuberculosis CIPT 14001002 were obtained from Institut Pasteur collection and were used for the preparation of mycolic acid standards. Mycobacteria were maintained on Lowenstein-Jensen medium slants at $4^{\circ} \mathrm{C}$. For extraction of mycolic acids, the strains were grown on Lowenstein-Jensen medium at $35-37^{\circ} \mathrm{C}$. Incubation temperature for M. marinum, M. gordonae and $M$. chelonae was $30^{\circ} \mathrm{C}$. The incubation period ranged from 7 to 10 days for rapidly growing species and from 25 to 32 days for slowly growing species.

Identification of mycobacteria by conventional methods - All mycobacteria strains were identified by their rate of growth, colonial morphology, pigmentation and biochemical properties (David et al. 1989).

Mycolic acid extraction and methylation procedures - The mycolic acid analysis was carried out according to the method proposed by Daffé et al. (1983), with some modifications. About 25-50 $\mathrm{mg}$ of mycobacteria, derived from LowensteinJensen medium, were dispersed into a $5 \%(\mathrm{w} / \mathrm{v})$ potassium hydroxide solution in 2-methoxyethanol. The mixture was maintained at $110^{\circ} \mathrm{C}$ for $2 \mathrm{hr}$, cooled and acidified with $1 \mathrm{ml}$ of sulfuric acid solution $(20 \% \mathrm{w} / \mathrm{w})$. Mycolic acids were then extracted by shaking the mixture twice with diethyl ether $(5 \mathrm{ml})$. The ether phase was decanted and washed three times with $2 \mathrm{ml}$ of water. Ether was removed on a water bath, and the mycolic acids were methylated by addition of $1 \mathrm{ml}$ of diazomethane ether solution.

Analytical methods and identification of mycolic acids - For TLC of mycolic acid, their methyl esters were spotted onto silica gel G $(20 \times 20$ $\mathrm{cm} \times 0.25 \mathrm{~mm}$ plates). Mycolic acids of the reference strains spotted together served as landmarks for the identification of mycolic acids extracted from the studied strains. One dimensional analysis was carried out by using two different elution systems: diethyl ether/petroleum ether $(12: 88 \mathrm{v} / \mathrm{v})$, with three developments of the chromatogram, and dichlorometane with a single development (Daffé et al. 1983). The presence of the separated components was revealed by spraying the chromatograms with $0,01 \%(\mathrm{w} / \mathrm{v})$ rhodamine in phosphate buffer (Daffé et al. 1983).

\section{RESULTS}

The sources and identification of 861 strains analyzed by conventional biochemical method are presented in Table I. Ninety percent of human's strains were M. tuberculosis (480 strains). Several other species of mycobacteria were identified from human infection. Mycobacterium avium complex (MAC) was the second in incidence, corresponding to $4.5 \%$ (24 strains). The major strain isolated from frogs was M. marinum (89.3\%) and from the environment was M. fortuitum (38.5\%) and other fast growing mycobacteria (FGM) $(19.4 \%)$.

\section{TABLE I}

Sources and species of 861 mycobacteria identified by conventional biochemical method

\begin{tabular}{lrrr}
\hline & Humans & Frogs & Water \\
\hline MAC ${ }^{a}$ & 24 & - & 5 \\
M. chelonae & 5 & 2 & 7 \\
M. fortuitum & 7 & - & 105 \\
FGM $^{b}$ & - & 3 & 53 \\
M. gordonae & 7 & 1 & 49 \\
M. kansasii & 1 & - & 2 \\
M. marinum & 2 & 50 & 2 \\
M. scrofulaceum & 2 & - & 1 \\
M. simiae & 1 & - & - \\
M. smegmatis & - & - & 22 \\
M. terrae complex & - & - & 27 \\
M. tuberculosis complex & 480 & - & - \\
Unidentified mycobacteria & 3 & - & - \\
\hline Total & 532 & 56 & 273 \\
\hline
\end{tabular}

$a$ : Mycobacterium avium complex; $b$ : fast growing mycobacteria; M: Mycobacterium.

The mycolic acid composition of 861 strains is reported in Table II. The mycolic acids are designed by Roman numerals as follows: type I (long nonoxygenated mycolates), type II (short non-oxygenated mycolates), type III (methoxymycolates), type IV (ketomycolates), type V (epoxymycolates) and type VI (dicarboxylic mycolates) (Daffé et al. 1983). For differentiation between mycolates types II and III, two developing systems were used. Mycolates II and III show similar Rf values in diethyl etherpetroleum ether solvent, and both migrate just be- 


\section{TABLE II}

Mycolic acids profiles of 861 strains identified by classical procedures

\begin{tabular}{|c|c|c|c|}
\hline $\begin{array}{l}\text { Mycobacterium/ } \\
\text { (No. of strains) }\end{array}$ & $\begin{array}{l}\text { Mycolic acids of } \\
\text { types strains }\end{array}$ & $\begin{array}{l}\text { Mycolic acids of } \\
\text { strains analyzed }\end{array}$ & $\begin{array}{c}\% \text { of } \\
\text { positivities }\end{array}$ \\
\hline $\operatorname{MAC}^{a}(29)$ & I. IV. VI & I. IV. VI & 100 \\
\hline M. chelonae (14) & I. II & I. II & 100 \\
\hline \multirow[t]{2}{*}{ M. fortuitum (112) } & I. $\mathrm{V}$ & I. V & 93 \\
\hline & & I. (II). V & 7 \\
\hline MAC $+M \cdot$ fortuitum $^{b}(01)$ & & I.IV.V.VI & \\
\hline \multirow[t]{3}{*}{$\mathrm{FGM}^{c}(56)$} & & I. VI & 80 \\
\hline & & I. II. VI & 13 \\
\hline & & I. IV. VI & 7 \\
\hline \multirow[t]{3}{*}{ M. gordonae (57) } & I. III. IV & I. III. IV & 90 \\
\hline & & I. III. IV. VI & 8 \\
\hline & & I. IV. VI & 2 \\
\hline M. kansasii (03) & I. III. IV & I. III. IV & 100 \\
\hline M. marinum (54) & I. III. IV & I. III. IV & 100 \\
\hline M. scrofulaceum (03) & I. IV. VI & I. IV. VI & 100 \\
\hline M. simiae $(01)$ & I. II. IV & I. II. IV & \\
\hline \multirow[t]{2}{*}{ M. smegmatis (22) } & I. V & I. V & 78 \\
\hline & & I. (II). V & 22 \\
\hline M. terrae complex (27) & I. VI & I. VI & 100 \\
\hline \multirow[t]{2}{*}{ M. tuberculosis complex (480) } & I. III. IV & I. III. IV & 99 \\
\hline & & I. IV $d$ & 1 \\
\hline MAC + M. tuberculosis ${ }^{b}(02)$ & & I.III.IV.VI & \\
\hline
\end{tabular}

a: Mycobacterium avium-intracellulare complex; $b$ : mixed infection; $c$ : fast growing non-pathogenic mycobacteria $d$ : BCG.

low the mycolate type I. However, in dichloromethane, mycolate III migrates below the mycolate II and here its Rf value is similar to that of mycolate IV. Typical thin-layer chromatograms of the mycolic acids methyl-esters are shown in Figs 1 and 2.

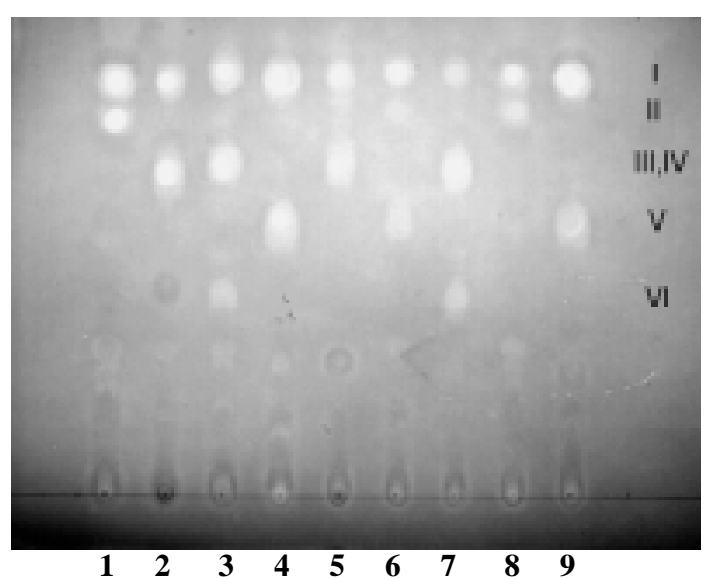

Fig. 1: chromatogram of mycolic acid methyl esters. Solvent: dichloromethane. Lines 1 to 4: reference strains. Lines 5 to 9: strains analyzed. 1: Mycobacterium chelonae CIPT 14042003; 2: M. tuberculosis CIPT 14001002; 3: M. avium CIPT 14031001; 4: M. fortuitum CIPT 14041001; 5: M. tuberculosis; 6: M. smegmatis; 7: M. scrofulaceum, 8: M. chelonae; 9: M. fortuitum.
MAC, M. chelonae, M. kansasii, M. marinum, M. scrofulaceum, M. terrae complex and M. simiae identified, presented mycolic acids profiles in accordance with the type strains. In $99 \%$ of $M$. $t u$ berculosis, $93 \%$ of $M$. fortuitum and $90 \%$ of $M$.

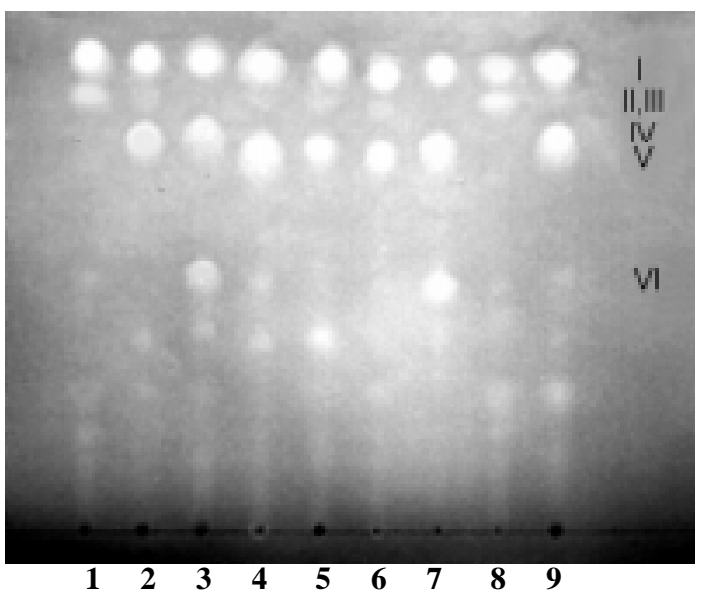

Fig. 2: chromatogram of mycolic acid methyl esters. Solvent: diethyl ether-petroleum ether. Lines 1 to 4 references strains. Lines 5 to 9-strains analyzed. 1: Mycobacterium chelonae CIPT 14042003; 2: M. tuberculosis CIPT 14001002; 3: M. avium CIPT 14031001; 4: M. fortuitum CIPT 14041001; 5: M. tuberculosis; 6: M. smegmatis; 7: M. scrofulaceum; 8: M. chelonae; 9: M. fortuitum. 
gordonae the mycolic acid profiles were in agreement with corresponding species (Minnikin et al. 1984). One percent of $M$. tuberculosis gave mycolates I and IV that are characteristic of BCG (Calmet-Guérin bacillus) (David et al. 1989). In this group, by additional biochemical tests, we confirmed identification of BCG.

M. gordonae strains have mycolic acids I.III.IV, but in $2 \%$ of them we found mycolic acid profile I.IV.VI that is common in M. scrofulaceum and MAC (David et al. 1989). After repeating the biochemical tests, we confirmed those strains as $M$. scrofulaceum. In $8 \%$ of $M$. gordonae we found mycolates I.III.IV.VI and this group was differentiated from the type strains (acids I, III and IV) only by their mycolic acids profiles, since both exhibit identical physiological and biochemical properties. Excluding M. chelonae, M. fortuitum and $M$. smegmatis, all of other fast growing mycobacteria (FGM) had mycolic acids I and VI, with or without types II or IV too.

The conventional method was not able to identify $0.6 \%$ of the human isolated strains (Table I), which were characterized by mycolate TLC as involved with mixed infections, as associations of $M$. tuberculosis and MAC or MAC and M. fortuitum.

\section{DISCUSSION}

M. tuberculosis is the most common agent of human tuberculosis in Brazil (Kritski et al. 1995) and for this species the identification by the conventional method agrees in $98 \%$ with the mycolates TLC. Tuberculosis caused by other members of M. tuberculosis complex is clinically indistinguishable of the one caused by M. tuberculosis, and their prevalence is unknown in most developing countries because of their limited laboratory facilities (Covisi et al. 1998). In this sense, the TLC analysis makes easy the distinction between $M$. tuberculosis and M. bovis variety BCG, that was first identified by its mycolate profile (Table II) and then confirmed by classical biochemical tests.

MAC infection is the second most important mycobacteriosis in Brazil, frequently associated to AIDS (Saad et al. 1997). In this study the members of this complex were easily identified by their mycolic acids I, IV and VI.

Mycolic acids analysis by TLC is becoming a good tool to detect mixed infections, as it may be concluded from this work: two cases of mixed infection by M. tuberculosis and MAC and one case by MAC and $M$. fortuitum. Lévy-Frébault et al. (1987) reported that they could distinguish $M$. simiae from M. avium by mycolates TLC in a mixed infection. This method also allowed the correct identification of potentially pathogenic $M$. scrofulaceum, misidentified as the saprophytic $M$. gordonae, and to detect $M$. simiae, a rare species, sometimes misidentified as M. tuberculosis or $M$. avium by biochemical tests (Wayne et al. 1991). Lévy-Frébault et al. (1986) performing mycolic acids TLC analyses of 133 strains of MAC, found that about $10 \%$ of those were in fact $M$. simiae.

Among the FGM species only M. fortuitum and $M$. chelonae are commonly found as human pathogens (Hijjar 1992). The identification of these mycobacteria is very hard when using the conventional method (David et al. 1989). M. fortuitum with mycolic acids I and V and M. chelonae with I and II were easily identified among our samples by TLC. The usefulness of mycolic acid analysis for FGM was described by Butler and Kilburn (1990), which utilized another chromatographic technique for mycolic acids identification, namely the high efficiency liquid chromatography (HPLC).

The conventional biochemical methods were unable to discriminate $8 \%$ of our frog and environmental isolated mycobacteria, which were differentiated from the type strains of $M$. gordonae only by their mycolic acids profiles. This result is interesting because Butler et al. (1996) also describe the occurrence of two different mycolic acids chromatotypes for $M$. gordonae analyzed by HPLC method. For Leite et al. (1989) the mycolic acids determination is of particular interest for environmental mycobacteria identification, mainly those not frequently isolated from humans.

In our four years experience we concluded that, mycolic acids analysis by TLC joined with conventional biochemical method, is a valuable tool for mycobacteria identification. This proceeding has allowed us to detect and identify all strains frequently isolated from human, environment and frog. Mycolic acids determination by TLC is a very simple technique and useful for the first step screening in mycobacteria identification. Joined with conventional methods it detects rare or new species, as well as mixed infections, undetectable by the classical tests alone.

\section{ACKNOWLEDGMENTS}

To Prof. Petr Melnikov for language revision.

\section{REFERENCES}

Butler WR, Kilburn JO 1990. High-performance liquid chromatography patterns of mycolic acids as criteria for identification of Mycobacterium chelonae, Mycobacterium fortuitum and Mycobacterium smegmatis. J Clin Microbiol 28: 2094-2098.

Butler WR, Floyd MM, Silcox V, Desmond E, Duffey PS, Guthertz LS, Gross WM, Jost KC, Ramos LS, Thibert L, Warren N 1996. Standardized Method for HPLC Identification of Mycobacteria, p. 45-46. US Department of Health and Human Services, Pub- 
lic Health Service-CDC, Atlanta, USA.

Covisi O, Grange JM, Daborn CJ, Raviglione MC, Fujikura T, Cousins D, Robinson RA, Huchzermeyer HFAK, Kantor I, Meslin FX 1998. Zoonotic tuberculosis due to Mycobacterium bovis in developing countries. Emerg Infect Dis 4: 59-70.

Daffé M, Lanéelle MA, Asselineau C, Lévy-Frébault V, David H 1983. Intérêt taxonomique des acides gras des mycobactéries; proposition d'une méthode d'analyse. Ann Microbiol (Paris) 134B: 241-256.

David H, Lévy-Frébault V, Thorel MF 1989. Méthodes de Laboratoire pour Mycobactériologie Clinique, Institute Pasteur, Paris, 85 pp.

Falcão DP, Valentini SR, Leite CQF 1993. Pathogenic and potentially pathogenic microorganisms as contaminants of fresh water from different sources. Water Res 27: 1737-1741.

Goodfellow M, Magee JG 1998. Taxonomy of mycobacteria, p. 1-71. In PRJ Gangadharam, Mycobacteria I, Basic Aspects, Chapman \& Hall Medical Microbiology Series, New York.

Hijjar MA 1992. Epidemiologia da tuberculose no Brasil. Informe Epidemiológico do SUS, Brasília 1: 53-87.

Hines ME, Fraziers KS 1993. Differentiation of mycobacteria on the basis of chemotype profiles by using matrix solid-phase dispersion acid thin-layer chromatography. J Clin Microbiol 31: 610-614.

Kritski A, Dalcomo MP, Bravo de Souza R, Hollanda,T, Gontijo Filho PP, Fiuza de Mello FA 1995. Associação tuberculose e infecção pelo HIV no Brasil. Bol Of Sanit Panam, Washington 118: 542554.

Leite CQF, Barreto AMW, Leite SRA 1995. Thin-layer chromatography of mycobactins and mycolic acids for the identification of clinical mycobacteria. Rev Microbiol 26: 192-199.
Leite CQF, Giannini MJSM, Falcão DP, Lévy-Frébault V, David H 1989. Presence of Mycobacterium marinum and other opportunistic mycobacteria in swimming pool waters in Araraquara, SP. Rev Microbiol 19: 354-359.

Lévy-Frébault V, Goh KS, David H 1986. Mycolic acid analysis for clinical identification of Mycobacterium avium and related mycobacteria. J Clin Microbiol 24: 835-839.

Lévy-Frébault V, Panzon B, Buré A, Katlama C, Marche C 1987. Mycobacterium simiae and Mycobacterium avium-M. intracellulare mixed infection in acquired immune deficiency syndrome. J Clin Microbiol 25: 154-157.

Luquin M, Ausina V, Calahorra FL, Belda F, Barceló MG, Celma C, Prats G 1991. Evaluation of practical chromatographic procedures for identification of clinical mycobacteria. J Clin Microbiol 29: 120-130.

Minnikin DE, Minnikin SM, Parlett JH, Goodfellow M, Magnusson M 1984. Mycolic acid patterns of some species of Mycobacterium. Arch Microbiol 139: 225231.

Saad MHF, Vincent V, Dawson DJ, Palari M, Ferrazoli L, Fonseca LS 1997. Analysis of Mycobacterium avium complex serovars isolated from AIDS patients from southeast Brazil. Mem Inst Oswaldo Cruz 92: 471-475.

Wayne LG, Good RC, Krichevsky MI, Blaclock Z, David HL, Dawson D, Gorss W, Hawkins J, Lévy-Frébault V, McManus C, Portaels F, Gerdes-Rusch S, Schroeder KH, Siliox VA, Tsukamura M, Van Den Breen L, Yakrus MA 1991. Fourth report of the cooperative open ended study of slowly growing mycobacteria by the international working group on mycobacterial taxonomy. Intern J Syst Bacteriol 41: 463-472. 
